\title{
DEMOCRACIA DIRETA, AÇÃO DIRETA E AUTOGESTÃO: O CASO DO MOVIMENTO DE OCUPAÇÕES ESTUDANTIS NA AMÉRICA LATINA'
}

\author{
GuILHerme XAVIER DE SANTANA \\ Universidade Federal do Rio de Janeiro (UFRJ), Rio de Janeiro, Brasil
}

\begin{abstract}
Resumo: O presente trabalho utiliza conceitos como democracia e movimentos sociais, pelo viés das interpretações político-filosóficas vinculadas à corrente anarquista com o intuito de analisar o fenômeno das ocupações estudantis nos anos de 2015 e 2016. Princípios como democracia direta, ação direta e autogestão serão centrais para balizar nosso debate e mostrar similitudes das medidas políticas adotadas por estudantes secundaristas com a prática libertária.
\end{abstract}

Palavras-chave: Democracia Direta. Movimentos Sociais. Autogestão. Ocupações Estudantis.

INTRODUÇÃO

Ao longo da história da filosofia, ciência política, história e ciências humanas em geral o conceito de democracia sempre foi um assunto intensamente debatido e cercado de diversas interpretações. Intelectuais de diferentes momentos históricos e locais do mundo, correntes de pensamento das mais diversas buscaram mostrar seus pontos de vista do que seria de fato o conceito de democracia e sua prática cotidiana.

Autores recentes buscam dar luz a esse debate, atualizando, ressignificando, atribuindo outros sentidos de análise sobre o assunto com referências das mais diversas. De liberais e conservadores, passando por marxistas e anarquistas, todas as correntes possuem interpretações peculiares a respeito de como pode funcionar de fato uma democracia.

Será foco de nosso trabalho problematizar a democracia, principalmente, num primeiro momento, a partir da noção de democracia direta, aliando a perspectiva democrática ao longo da história e a interpretação que ela obtém enquanto um princípio da filosofia anarquista.

Além da noção teórica de democracia direta, as práticas relativas às noções de ação direta e da autogestão também serão trabalhadas como conceitos e táticas políticas reivindicadas por anarquistas, mas que sempre foram executadas por diversos movimentos sociais ao longo da história.

Após isso, será nosso objetivo conectar os conceitos mencionados acima ao fenômeno das ocupações escolares que aconteceram em diversos estados como, por 
exemplo, São Paulo e Rio de Janeiro, que servirão de um breve modelo para apresentar o trabalho a partir de uma perspectiva política libertária.

Por fim problematizaremos duas questões de diferentes naturezas: o conceito de movimentos sociais ligado ao fenômeno das ocupações estudantis, além de tratar de forma breve a perseguição e repressão que os secundaristas enfrentaram em seus contextos de mobilização e luta.

\section{DEMOCRACIA DIRETA: DA ÁGORA NA DEMOCRACIA GREGA À ÀGORA CONTEMPORÂNEA}

Existem muitos estudos acerca da história política e da filosofia desenvolvida no período da Grécia Antiga. A própria filosofia ateniense vigente naquela época era palco de disputas entre aqueles que deixaram um legado de reflexão que até os dias atuais servem de influência nos campos de conhecimentos já citados.

Sobre a democracia grega, o intelectual Moses I. Finley analisa, em sua obra "Democracia antiga e moderna" (1988), aspectos diversos da democracia ateniense, aprofunda como se davam os processos de deliberação, construção de assembleias, dentre outros mecanismos de funcionamento da dinâmica política daquele período na Grécia.

Finley (1988), ao mencionar a importância histórica dos gregos para definir o que seriam formulações ligadas à teoria política da época, diz que

Os gregos - e isso ninguém poderá contestar - foram os primeiros a pensar sistematicamente sobre política, a observar, descrever e, finalmente, formular teorias políticas. Por boas e suficientes razões, a única democracia grega que podemos estudar com profundidade a de Atenas nos séculos $V$ e IV a.C., foi também a mais fecunda intelectualmente. Foi a produção escrita grega originada da experiência ateniense que os séculos XVIII e XIX conheceram, na medida em que a leitura da História teve um papel no despertar e no desenvolvimento das modestas teorias democráticas. (FINLEY, 1988, p. 27).

O historiador, em sua obra, também busca diferenciar mecanismos de decisões politicamente tomados pelos gregos na antiguidade e a questão da representação política da qual estamos popularmente acostumados. Com relação a esse ponto e o modelo político existente na prática, nas palavras do autor,

[...] a democracia ateniense era direta, não representativa, em dois sentidos. O comparecimento à Assembleia soberana era aberto a todo cidadão, e não havia burocracia ou funcionários públicos, exceto uns poucos escriturários, escravos de propriedade do Estado que faziam registros inevitáveis, como cópias de tratados e leis, listas de contribuintes inadimplentes e similares. O governo era, 
SANTANA, G. X. de.

\begin{abstract}
assim, "pelo povo", no sentido mais literal. A Assembleia, que detinha a palavra final na guerra e na paz, nos tratados, nas finanças, na legislação, nas obras públicas, em suma, na totalidade das atividades governamentais, era um comício ao ar livre, com tantos milhares de cidadãos com idade superior a 18 anos quanto quisessem comparecer naquele determinado dia. Ela se reunia frequentemente durante todo o ano, no mínimo quarenta vezes, e, normalmente, chegava a uma decisão sobre o assunto a discutir em um único dia de debate, em que, em princípio, todos os presentes tinham o direito de participar, tomando a palavra. (FINLEY, 1988, p. 31).
\end{abstract}

Nesse sentido, podemos dizer que esses espaços de construção, debate e deliberação em Atenas na história antiga são chamados de ágora. Tal conceito tem sido ressignificado por autores do campo da ciência política que buscam aprofundar o tema da democracia na contemporaneidade. A partir da leitura de Dupuis-Déri (2019), que em seu texto cita Detienne (2003), podemos afirmar que

A ágora é, primeiro, o lugar onde as assembleias ocorrem; [...] Mais especificamente, a ágora, tanto no singular quanto no plural, significa "a disputa de discursos", "os debates que ocorrem em assembleia" sobre "uma questão concernente à comunidade, ou seja, todos aqueles que se reuniram e que em princípio, gozam do mesmo direito de serem ouvidos. (DETIENNE, 2003, p. 17 apud DUPUIS-DÉRI, 2019, p. 13).

Buscando uma reflexão e também atualização do conceito de democracia direta e o uso dos espaços públicos como arena - uma espécie de "ágora contemporânea", relacionando a acontecimentos contemporâneos, podemos dizer que as ideias filosóficas e políticas voltadas ao campo dos movimentos sociais ligados às práticas libertárias são as que mais se aproximam e de fato reivindicam a democracia direta.

A teoria libertária possui suas raízes ainda no século XIX a partir das reflexões vindas da prática e tática política de correntes do movimento operário na Europa. Para Pierre Joseph Proudhon - que é considerado um dos primeiros anarquistas da história a anarquia seria

uma forma de governo ou constituição, na qual a consciência pública ou privada, formada pelo desenvolvimento da ciência e do direito, é por si só suficiente para a manutenção da ordem e para a garantia de todas as liberdades. (PROUDHON, 1929, p. 350 apud LAZARO, 2006, p. 12).

Podemos afirmar que a teoria e prática anarquista antes de tudo busca romper com todas as formas de autoridade e hierarquias institucionalizadas, em todos os níveis políticos e sociais. Outro teórico e militante anarquista clássico que podemos mencionar 
é o italiano Errico Malatesta, que define os ideais anarquistas de forma histórica da seguinte maneira:

\begin{abstract}
O anarquismo nasceu da revolta moral contra as injustiças sociais. Quando apareceram homens que se sentiram sufocados pelo ambiente social em que eram obrigados a viver, que sentiram a dor dos demais como se ela fosse a sua própria, e quando estes homens se convenceram de que boa parte do sofrimento humano não é consequência inevitável das leis naturais ou sobrenaturais inexoráveis, mas, ao contrário, que deriva de realidades sociais dependentes da vontade humana e que podem ser eliminados pelo esforço humano, abria-se então o caminho que deveria conduzir ao anarquismo. (MALATESTA, 2009, p. 4).
\end{abstract}

O anarquismo não é uma teoria estática e, assim como qualquer outra filosofia, ideologia ou corrente política, atualiza-se de acordo com os contextos históricos e sociais. Nesse sentido, vale trazer para contribuição no presente artigo as ideias do antropólogo anarquista contemporâneo David Graeber (2015), em seu livro “Um projeto de democracia".

Nessa obra, o autor narra e analisa o contexto anterior, durante e posterior referente ao movimento Occupy Wall Street, que aconteceu em 2011 nos Estados Unidos, mostrando que a organização dos movimentos de ocupação realizados na praça em frente à Bolsa de Valores de Nova lorque traz luz às práticas da democracia direta, como construção de consenso, deliberação de forma direta e sem representantes do Estado interferindo no processo, dentre outros aspectos em um fenômeno político atual.

A tradição dos anarquistas exaltarem a liberdade e a igualdade ao longo da história, que Graeber (2015) relaciona com o ideal democrático, é algo que merece ser mencionado, como no trecho que diz que,

\footnotetext{
Os anarquistas idealizam um mundo baseado na igualdade e na solidariedade, no qual os seres humanos seriam livres para se associar entre si a fim de buscar uma infindável variedade de sonhos, projetos e concepções daquilo que considerem valioso na vida. (GRAEBER, 2015, p. 188).
}

Nesse sentido, vale fazer referência ao trabalho do Francis Dupuis-Déri, "Quem tem medo do povo? O debate entre Ágorafobia Política e Ágorafilia Política" (2019).

Ágorafobia política significa os "medos das pessoas reunidas em uma ágora formal ou informal. As comparações e metáforas que os pensadores ágorafóbicos usam para falar do "povo" também revelam o medo que elas abrigam" (DUPUIS-DÉRI, 2019, p. 13 , grifo do autor). Já a noção de ágorafilia política se define "como uma simpatia em relação às pessoas reunidas com o propósito de tomar decisões coletivas. Para ágorafilia 
SANTANA, G. X. de.

política, a igualdade prevalece porque todos os membros da comunidade podem participar da ágora" (DUPUIS-DÉRI, 2019, p. 14, grifo do autor).

Ao longo de seu texto, Dupuis-Déri (2019) faz uma interessante relação entre anarquia e ágorafilia política dizendo que

\begin{abstract}
A ágorafilia política, portanto, se subdivide em democracia e anarquia. Em uma democracia direta, o processo deliberativo culmina em uma votação pela qual a maioria mantém influência sobre a maioria. Já na anarquia, o processo decisório e deliberativo é consensual - o governo de todos por todos. (DUPUIS-DÉRI, 2019, p. 25).
\end{abstract}

Portanto, entendemos que a democracia direta rompe com o paradigma da representatividade. Valorizar a participação direta de todos os envolvidos no ambiente político no qual tem se debatido alguma pauta específica ou genérica, ou ainda embates políticos relacionados a assuntos diversos e que interferem no cotidiano da população é radicalmente o oposto do que observamos na dita democracia representativa, na qual, muitas vezes, a participação política se resume no exercício do voto, por meio do sufrágio universal, de tempos em tempos.

Luis Felipe Miguel (2002) reforça que essa tradição teórica que defende a democracia representativa enquanto um regime político praticamente irrefutável politicamente tem suas bases em autores como Mosca, Pareto, Ortega y Gasset e Schumpeter.

Sobre o mesmo assunto, o geógrafo, militante e anarquista Piotr Kropotkin, em sua obra "Palavras de um revoltado" (2005), faz apontamentos importantes ao revelar que ao longo da história a conquista do voto foi por um momento uma ameaça aos poderosos, mas com o passar do tempo percebeu-se o seu limite e as suas fraquezas, mostrando que de nada ele iria servir para derrubar o Estado e construir-se uma nova ordem. Dito isso, o autor indaga:

\footnotetext{
O sufrágio universal pode algumas vezes proteger até certo ponto a burguesia contra as usurpações do poder central, sem que ela necessite recorrer amiúde à força para se defender. Pode servir para restabelecer o equilíbrio entre duas forças, que disputam o poder, sem que os rivais sejam levados a esfaquear-se, como se fazia outrora. Em nada pode ajudar, porém, se se trata de derrubar, ou até limitar o poder, abolir a dominação. Excelente instrumento para resolver, de maneira pacífica, as querelas entre governantes - de que utilidade poderá ser ele para os governados?

A história do sufrágio universal não está nem aí para mostrá-lo? Enquanto a burguesia temeu que o sufrágio universal se tornasse, nas mãos do povo, uma arma que pudesse voltar contra os privilegiados, combateu-o aguerridamente. Todavia, no dia em que Ihe foi provado, em 1848, que o sufrágio universal não deve ser temido e que, ao contrário, conduz-se muito bem um povo com autoridade absoluta por meio do sufrágio universal, ela o aceitou na
} 
hora. Agora, é a própria burguesia que se coloca como seu defensor, porque compreende que ele é uma excelente arma para manter sua dominação, mas absolutamente impotente contra os privilégios da burguesia. (KROPOTKIN, 2005, p. 46-47).

Ainda na mesma obra, o anarquista russo avança na análise ao criticar a conquista de liberdades políticas nos marcos legais do sistema representativo e que de certa forma fora moldado pela burguesia. Dentre os exemplos, além do sufrágio universal, Kropotkin (2005) cita a liberdade de imprensa e algumas leis colocadas em prática. Como o próprio militante e intelectual diz: "As liberdades não são dadas, são conquistadas" (KROPOTKIN, 2005, p. 50).

A seguir desenvolveremos as questões ligadas à democracia direta - atuação política que vai para além da lógica da representação, dois dos principais conceitos e princípios reivindicados pelos anarquistas ao longo da história: ação direta e autogestão. Vamos relacionar ambos os conceitos com as táticas e práticas de ocupações muito utilizadas por diversos movimentos sociais como forma de mobilização para reivindicar suas pautas.

AÇÃO DIRETA, AUTOGESTÃO E DIÁLOGOS COM A CONSTRUÇÃO DE UMA DEMOCRACIA DIRETA

Ação direta trata-se de um conceito e prática ao longo da história que não é exclusiva de quem reivindica a política anarquista, mas que possui relação intrínseca a quem costuma construir tal filosofia política no cotidiano.

Segundo Silva (2018),

O conceito de ação direta apareceu por escrito pela primeira vez no Congresso de Amiens (1906): "a ação econômica deve-se exercer diretamente contra o patronato". O termo, no entanto, já era usado no contexto do movimento sindicalista francês na década de 1890, resumindo-se a "ação industrial", como "greves, boicotes e sabotagens". (SILVA, 2018, p. 193).

Já Moraes (2018a), em sua obra "Governados por quem? Diferentes plutocracias nas histórias políticas de Brasil e Venezuela", diz que

Os libertários defendem a ação direta como meio de melhorar as condições de vida da humanidade, isto é, a auto-organização dos trabalhadores, homens e mulheres, em uma palavra, dos governados, que juntos devem lutar pela libertação total e pela construção de um mundo novo, a verdadeira emancipação social, sem intermediação alheia. (MORAES, 2018a, p. 35). 
SANTANA, G. X. de.

A noção de democracia para os anarquistas vai muito além das instituições ditas democráticas, como estamos acostumados a acompanhar no cotidiano da política tradicional e institucional. Ou seja, os libertários não relacionam a noção de democracia com o Estado enquanto o detentor e centralizador dessas instituições, diferentemente de liberais, marxistas e outras correntes políticas que avançam suas reflexões até o aparato estatal. Moraes (2018a) chama atenção para essa exaltação e dependência do Estado para formular políticas e nas suas atuações e discursos cotidianos de Estadolatria².

Nesse sentido, Moraes (2018a) e outros autores, como David Graeber, entendem que uma democracia direta se aproxima dos ideais e princípios políticos anarquistas, pois é somente por meio da atuação direta dos chamados governados que pode existir um "governo do povo" ${ }^{3}$. E esse chamado "governo do povo" é sinônimo de autogoverno, que os anarquistas chamam de autogestão (GRAEBER, 2015; MORAES, 2018a).

Ainda na interpretação de Moraes (2018a), o autor entende que

[...] os anarquistas acreditam no autogoverno ou autogestão. Se partimos da premissa segundo a qual devamos ser governados, logo entendemos que não temos capacidade de autogoverno. Com esta assertiva, está todo o fundamento da autoridade e da tutela contra a qual os anarquistas lutam. Toda forma de governo será sempre uma imposição de uns sobre outros, atentando contra a liberdade dos governados. Mesmo que o governo tenha boas intenções, ele sempre se sustentará na miragem de que os governados são incapazes de autogovernar-se e/ou necessitam de controle.

No sentido oposto, os anarquistas defendem a livre associação entre os indivíduos para gerirem o produto de seu trabalho e todas as demais questões da sociedade em comunas livres, sem patrão, Estado, ou qualquer forma de opressão. Eles devem constituir-se pela livre associação entre os indivíduos. Ou seja, as pessoas escolhem aquelas com as quais querem associar-se e criar ou manter algum tipo de produção para a sociedade. A junção de diversas comunas comporá a federação. $\mathrm{O}$ anarquismo defende os fundamentos do federalismo como forma de organização social. Ademais, o preceito da autodeterminação dos povos é fundamental para a teoria anarquista e viabiliza a superação do capitalismo e suas formas de opressão. (MORAES, 2018a, p. 34).

Outro anarquista que exalta e reivindica a democracia direta em seus escritos é o norte-americano Murray Bookchin. O autor entende que a democracia é a gestão direta da sociedade em assembleias face a face, na qual a política é definida pelos cidadãos residentes e a administração feita a partir de delegação com cargos rotativos, ou seja, a partir de uma autogestão. Bookchin diz também que "devemos recuperar não apenas a dimensão socialista do anarquismo, mas sua dimensão política: a democracia" (BOOKCHIN, 2010, p. 47). 
Já a respeito do conceito e prática de autogestão, vale apresentar o que diz o grego radicado na França, Cornellius Castoriadis. A partir de uma citação do texto de Rodrigues (2004), o filósofo também amplia o debate sobre o assunto ao dizer que

\begin{abstract}
A autogestão implica a possibilidade de participação direta e igualitária de qualquer membro da sociedade no processo de tomada de decisões (instituição de leis, normas, organização do trabalho, distribuição da riqueza, etc.) [...]; prevê também o controle efetivo do processo de tomada de decisões pelos próprios envolvidos, em um ambiente protegido (mas não completamente desprovido) das relações heterônomas que cristalizam hierarquias divisões entre dirigente e dirigidos (CASTORIADIS, 1982 apud RODRIGUES, 2012, p. 265).
\end{abstract}

Avançaremos agora para comentar a respeito das táticas de ocupações como reivindicação política na história e que tem sido reatualizada pela juventude estudantil do país e de outras partes do mundo.

\title{
SOBRE A TÁTICA POLITICA DE OCUPAÇÕES
}

Nosso intuito neste momento do artigo é resgatar o método e tática da ocupação como recurso político em diferentes contextos históricos, tais como as ocupações de fábricas na virada do século XIX e XX, que tinham por intuito direitos e condições de trabalho dignas; os sovietes no processo da Revolução Russa e anterior à chegada dos bolcheviques em 1917; as ocupações de prédios, estabelecimentos, de locais públicos durante a Guerra Civil Espanhola na região da Catalunha; ocupações em universidades e fábricas na França ao longo do período conhecido como Maio de 1968; as ações diretas no episódio político que já citamos, chamado de Ação Global dos Povos; as ocupações que se tornaram com um tempo referências revolucionárias contemporâneas na região de Chiapas, no México, pelo Exército Zapatista de Libertação Nacional (EZLN) e a Revolução Curda, ${ }^{4}$ que vem ocorrendo baseada no Confederalismo Democrático ${ }^{5}$ e que também podemos considerar uma ação direta em termos totais na região.

Também podemos mencionar aqui no Brasil, já no início do século, as ocupações de fábrica durante greves gerais; as escolas operárias nas primeiras décadas do século XX; e, mais recente, temos como exemplo as ocupações sem-teto na luta por moradia e contra a especulação imobiliária nos centros urbanos brasileiros; as ocupações sem-terra contra o latifúndio e as ocupações de praças públicas - ocupações estas que, desde a Primavera Árabe, ocorreram em diversos locais do mundo: em alguns países da região do norte da África e em regiões vizinhas na Europa e Ásia; nos Estados Unidos, onde a Ocupação da Praça de Wall Street foi a que teve mais destaque diante de várias outras praças no país; e também o Movimento dos Indignados na Espanha. 
SANTANA, G. X. de.

Sobre a tática de ocupações, Castells (2017) reforça que,

Frequentemente, prédios são ocupados, seja por seu simbolismo, seja para afirmar o direito do uso público de prioridades ociosas, especulativas. Ao assumir e ocupar o espaço urbano, os cidadãos reivindicam sua própria cidade, uma cidade na qual foram expulsos pela especulação imobiliária e pela burocracia municipal. Alguns movimentos sociais historicamente importantes como a Comuna de Paris de 1871 ou as greves de Glasgow em 1915 (na origem da política de habitação pública na Grã-Bretanha), começaram como boicotes aos alugueis contra a especulação na área de moradia. $\mathrm{O}$ controle do espaço simboliza o espaço da vida das pessoas. (CASTELLS, 2017, p. 25).

Castells (2017), Graeber (2015) e Moraes (2018b) analisam esses acontecimentos contemporâneos defendendo que tais mobilizações e ações diretas promovidas em diferentes locais, mas em um período concomitante, se caracterizam por possuírem um DNA em comum que são a descentralização de poder nas ações e a atuação política feitas em rede, por meio da internet e pessoalmente, sem intermediários do poder constituídos pelo Estado (mandatos de políticos profissionais, partidos que disputam eleições, etc.).

A seguir vamos mostrar o caso das ocupações de escola que aconteceram em diversos locais do país entre os anos de 2015 e 2016 e que reverbera até os dias atuais nos movimentos sociais.

\section{O CONTEXTO DAS OCUPAÇÕES ESTUDANTIS...}

No ano de 2006 ocorreu um grande movimento de ocupações de escolas no Chile. As mobilizações aconteceram em todo o país e foi chamada de "Revolta dos Pinguins". As principais pautas dos estudantes eram referentes ao projeto de privatização do sistema de educação que vinha ocorrendo (e que de certa forma avançou por alguns anos depois). Essa mobilização do movimento estudantil chileno foi emblemática e influenciou diversas outras mobilizações tanto no país quanto em outros locais, como, por exemplo, no Brasil.

Zibas (2008) nos contextualiza da seguinte forma sobre como se deu o início do movimento:

[...] a primeira pauta de reivindicações dos estudantes era muito simples e carecia da dimensão política que veio a ganhar mais tarde. Constava principalmente dos seguintes itens: gratuidade do exame de seleção para a universidade, passe escolar grátis e sem restrições de horário para transporte municipal, melhoria e aumento da merenda escolar e reforma das instalações sanitárias em mau estado em muitas escolas. Essas questões foram quase imediatamente equacionadas ou atendidas pelo governo da 


\begin{abstract}
presidenta Bachelet. Todavia, a ampliação do debate nas assembleias estudantis e a adesão de outros agentes políticos, como o sindicato docente, vieram dar maior profundidade e amplitude à pauta inicial, que passou a incluir, entre outros pontos, a anulação da Lei Orgânica Constitucional de Ensino (LOCE) e a modificação ou anulação da JEC (Jornada Escolar Completa). (ZIBAS, 2008, p. 23).
\end{abstract}

Já no ano de 2015, cerca de 200 escolas da rede estadual foram ocupadas por estudantes em São Paulo contra o chamado plano de reorganização escolar, proposto pelo governador Geraldo Alckmin e seu partido, o PSDB. Sem diálogo com a comunidade escolar (corpo docente e discente, funcionários e responsáveis pelos estudantes), o plano tinha como um dos pontos principais o fechamento imediato de 93 escolas da rede estadual.

Segundo o governo, a proposta favoreceria a gestão das unidades e possibilitaria a adoção de estratégias pedagógicas focadas na idade e na fase de aprendizado dos alunos ${ }^{6}$.

Além da queixa de ausência de diálogo por parte do poder público, os estudantes de São Paulo também reclamavam das condições precárias pelas quais as escolas passavam, dando apoio à classe dos trabalhadores da educação. Esse processo de ocupação escolar se desencadeou em todo o estado, não só na capital ou na região metropolitana, e conseguiu fazer com que, por tempo indeterminado, o plano de reorganização fosse interrompido pela justiça ou governança jurídica, ${ }^{7}$ como aponta Moraes (2018a).

O movimento de ocupações escolares organizadas por secundaristas avançou para outros locais do Brasil e, em 2016, começou a se fortalecer no estado do Rio de Janeiro, onde as ocupações coincidiram com uma greve deflagrada no início de março do mesmo ano pela categoria, greve esta que viria a durar cinco meses e foi a que teve mais alta adesão, segundo o Sindicato Estadual de Profissionais da Educação (SEPE-RJ) ${ }^{8}$.

Vale ressaltar que, além de São Paulo e Rio de Janeiro - foco da presente pesquisa, o fenômeno se espalhou para outros estados do país, como Goiás ${ }^{9}$, Rio Grande do Sul ${ }^{10}$, Ceará ${ }^{11}$, Mato Grosso ${ }^{12}$, Pernambuco ${ }^{13}$, Paraná ${ }^{14}$, dentre outros.

O presente artigo ainda se trata de um trabalho preliminar, mas que aponta para algumas particularidades e características a partir de leituras e outros materiais, como filmes e matérias: 1) as ocupações estudantis possuíram um caráter heterogêneo, mas que se pautaram pela tática de ação direta, sem buscar intermediários da política institucional nos mais diversos locais onde a juventude se mobilizou; 2) a maior parte delas teve como protagonismo os estudantes em suas escolas por demandas específicas ou ligadas às políticas que geraram insatisfação da juventude de escolas públicas; 3 ) as táticas de ocupações foram acompanhadas de outras formas de mobilizações, como protestos de rua, integração e apoio de outros movimentos sociais; e, principalmente, 4) 
SANTANA, G. X. de.

a forma de atuação e organização, por meio da autogestão e exercendo uma democracia direta em grande parte das unidades escolares ${ }^{15}$.

\section{ENTENDENDO AS OCUPAÇÕES COMO UM MOVIMENTO SOCIAL}

De acordo com Gohn (2014, p. 23), "um movimento social é sempre expressão de uma ação coletiva e decorre de uma luta sociopolítica, econômica ou cultural". A autora destaca ainda que o termo movimento social enquanto produção teórica surgiu com Herbert Blumer em 1939.

De lá para cá diversas abordagens sobre o assunto foram tratadas, correntes teóricas diferentes se debruçaram e esmiuçaram a categoria movimentos sociais. Maria da Glória Gohn (2014) retrata que as divergências e mudanças de análises sobre os movimentos sociais sempre tiveram relação direta com a conjuntura social global (ou local), fenômenos políticos, avanços e retrocessos de algumas pautas dependendo do período, dentre outros aspectos.

Sobre as últimas décadas, Gohn (2014) nos mostra que,

No final do século $X X$ e início deste milênio, o tema dos movimentos sociais retoma um lugar central no plano internacional como objeto de investigação por intermédio do movimento antiglobalização, de uma nova perspectiva: como movimento global que rompe barreiras das nações e se torna não apenas internacional, mas transnacional. [...] As categorias de análise se alternam: redes sociais passam a ter, para vários pesquisadores, um papel até mais importante do que o movimento social. Mas eles as redefinem para redes de mobilização social. A questão da emancipação social persiste, mas restringe a não mais sob o crivo exclusivo da abordagem marxista. Território passa a ser uma categoria ressignificada e uma das mais utilizadas para explicar as ações localizadas, mas é uma nova concepção de território distante da geografia tradicional que a confundia com o espaço físico. (GOHN, 2014, p. 43-44).

Já Bringel (2009), ao incluir o movimento estudantil na agenda acadêmica e dialogando com os demais movimentos sociais, teoriza da seguinte forma a questão:

Os movimentos estudantis, da mesma forma que os das mulheres, camponeses, indígenas, urbanos e outros, são movimentos sociais. Essa afirmação que poderia parecer óbvia tem profundas implicações teóricas e, apesar de algumas exceções destacadas adiante, dista muito do trato que os movimentos estudantis receberam (e recebem), na maioria das análises, sobre os movimentos sociais. Sua aceitação dependerá fundamentalmente do conceito de movimentos sociais utilizado. No caso das lutas estudantis no Brasil, o termo "movimento" tem sido extensamente utilizado e escassamente debatido, em razão de seu uso num 
sentido laxo e ampliado, empregado há várias décadas, de forma quase imediata, quando um grupo de estudantes se mobiliza. (BRINGEL, 2009, p.100).

E, especificamente com relação às ocupações estudantis de 2015 e 2016, Gohn (2019) afirma que

\begin{abstract}
No novo ciclo de mobilizações pela educação, tanto no caso das ocupações de escolas públicas em 2015 como no caso das ETECs ${ }^{16}$ em 2016, uma característica de Junho de 2013 se repete: a falta de mediadores e a ausência de lideranças, ainda que haja uma organização e divisão interna de tarefas, apenas alguns estudantes têm a atribuição de se comunicar com a imprensa, dar entrevistas etc. O elemento comum se chama: movimento autonomista. Devem ser incluídos entre os novíssimos movimentos pela forma de agir, inovações que trazem i uso intensivo das redes sociais para toda organização, embora os princípios ideológicos sejam os mesmos. (GOHN, 2019, p. 49).
\end{abstract}

Contextualizando o movimento de ocupações com o conceito de "Novos Movimentos Sociais", trabalhado por Boaventura de Souza Santos (2005), percebemos que há uma conexão entre a prática dos estudantes e o conceito. O cientista social português aborda que

\begin{abstract}
A ideia da obrigação política horizontal entre os cidadãos e a ideia da participação e da solidariedade, que se concretizam na formulação da vontade geral, são as únicas ideias que verdadeiramente podem fundar uma nova cultura política e, em última instância, uma nova qualidade de vida pessoal e coletiva baseada na autonomia e no autogoverno, na descentralização e na democracia participativa, no cooperativismo e mesmo do pessoal, abre um imenso campo para o exercício da cidadania e, ao mesmo tempo revela as limitações da cidadania de extração liberal e também da cidadania social, restritas ao âmbito do estado e do político por ele constituído. (SANTOS, 2005, p. 184).
\end{abstract}

Entendemos que as contribuições dos autores acima conseguem dar conta e colocar o fenômeno das ocupações estudantis no campo político de análise e também no escopo de reflexões acerca de temáticas vinculadas aos estudos sobre movimentos sociais.

\title{
CONCLUSÃO
}


SANTANA, G. X. de.

Concluímos o artigo mostrando que os conceitos trabalhados e os exemplos mencionados são importantes para fazermos uma reflexão acerca de como os ideais e as táticas políticas libertárias, como a ação direta, a autogestão e a democracia direta estão sendo ressignificados em diversos movimentos sociais atualmente.

Importante dizer que a tática de ação direta por meio das ocupações do espaço público, de uma fábrica ou das escolas - como é o exemplo estudado aqui -, não pode ser pensada de forma separada das práticas que visam uma autogestão e a construção de democracia direta.

Lembramos ainda que a democracia direta exercida na Grécia Antiga - de maneira adaptada - pode servir como uma inspiração no que tange a forma de debate em espaços públicos e sem representação institucional interferindo no processo de alguma deliberação e construção política de forma coletiva.

Sendo assim, podemos afirmar que a experiência das ocupações de escolas, praças públicas, fábricas e outros exemplos citados se encontram no que Depuis-Déri (2019) chama de ágorafilia política. Para o autor canadense,

\begin{abstract}
(...) as pessoas devem governar a si mesmas para que a liberdade e a igualdade existam. Em um mundo guiado por princípios da ágorafobia política, não há nem liberdade e nem liberdade e as pessoas estão sob as influências de uma elite. (DUPUIS-DÉRI, 2019, p. 25).
\end{abstract}

A forma de luta direta e a busca por uma autogestão para se organizar, seja nas ocupações dos estudantes, em outras mobilizações da classe trabalhadora ou quaisquer outros movimentos sociais, servem para delimitar e apontar caminhos para evitar retrocessos referentes a aplicação de políticas que atingem a população mais frágil econômica e politicamente falando.

Importante ressaltar que as ocupações estudantis não se resumiram aos secundaristas do Chile em 2006, Brasil em 2015 e 2016, mas também ocorreram em outros locais da América Latina, como o Paraguai ${ }^{17}$ e Argentina ${ }^{18}$. Ainda no Brasil em 2016, mais de 80 universidades também foram ocupadas ${ }^{19}$. Os estudantes protestavam principalmente contra a Medida Provisória 746, que estabelece mudanças no ensino médio, e contra a Proposta de Emenda à Constituição (PEC) 241, do governo federal, que limita por 20 anos os gastos públicos - incluindo a área de educação. Até na África do Sul ocorreram mobilizações com protestos de rua e nas universidades por conta do projeto do governo que buscava cobrar mensalidades aos estudantes, dentre outras medidas privatistas ${ }^{20}$.

Entendemos que a democracia direta exercida pela juventude em escolas e universidades acaba por aplicar conceitos e práticas que dialogam com a filosofia anarquista como ação direta pelo fato de ocupar, sem intermediários e com pautas políticas definidas, um local que é público; autogestão, no sentido de estabelecerem dinâmicas de auto-organização estudantil no interior de cada unidade educacional; e colocando em prática a ágorafilia política, pois a juventude, com tais ações, se mostra 
disposta a atuar de forma igualitária, sem lideranças institucionais e em busca da liberdade que só pode ser conquistada de forma coletiva, e não individual.

Encerramos o artigo apontando que é importante entender que a teoria e prática política libertária continuam se atualizando em diversas frentes e interpretações que vão além de instituições, cujas táticas de luta se reinventam de acordo às necessidades, e as novas gerações, mesmo sem uma leitura prévia de conceitos e autores, consegue a partir da prática se aproximar de ideais clássicos como ação direta, democracia direta e autogestão. E acabam expondo algumas contradições no sistema e servem de exemplos a diversos movimentos sociais posteriormente. Acreditamos que essas sejam as principais reflexões que buscamos trazer neste artigo.

Artigo recebido em: 20/08/2020 Aprovado para publicação em: 17/11/2020

DIRECT DEMOCRACY, DIRECT ACTION AND SELF-MANAGEMENT: THE CASE OF THE STUDENT OCCUPATIONS IN LATIN AMERICA

ABSTRACT: The present work seeks to work on concepts such as democracy and social movements, through the bias of political-philosophical interpretations linked to the anarchist view in order to analyze the phenomenon of student occupations in the years 2015 and 2016. Principles such as direct democracy, direct action and self-management will lead our debate.

KEYWORDS: Direct Democracy. Social Movements. Self-Government. Student Occupancy.

DEMOCRACIA DIRECTA, ACCIÓN DIRECTA Y AUTOGESTIÓN: EL CASO DEL MOVIMIENTO DE OCUPACIÓN ESTUDIANTIL EN LATINOAMERICA

RESUMEN: El presente trabajo utiliza conceptos como democracia y movimientos sociales, a través de interpretaciones político-filosóficas vinculadas a la corriente anarquista con el fin de analizar el fenómeno de las ocupaciones estudiantiles en los años 2015 y 2016. Principios como democracia directa, acción directa y autogestión serán centrales para guiar nuestro debate.

PALABRAS CLAVE: Democracia Directa. Movimientos Sociales. Autogestión. Ocupaciones Estudiantiles. 


\section{NOTAS}

1 - Este trabalho é fruto de uma pesquisa em andamento que estou realizando no doutorado em História Comparada pela UFRJ (PPGHC-UFRJ).

2 - "[...] Nossa concepção de Estadolatria é absolutamente diferente da utilizada pelo pensamento ultraliberal, que defendem o Estado mínimo, exclusivamente, para garantir a propriedade, o patrimônio e o lucro dos proprietários. Essa concepção não aponta para o fim do Estado, mas, apenas, para um direcionamento de suas funções, com vistas a garantir o pleno funcionamento da economia capitalista, sem possibilidade de qualquer papel mais generoso para os governado. Assim, só o pensamento anarquista pode estabelecer a crítica ao Estado, enquanto instituição de coerção, de controle, de autoridade, que atenta contra a liberdade dos governados, opondo-se, frontalmente, à tradição da Estadolatria. Nos nossos termos, essa categoria funciona como uma camisa de força, que obsta reflexões teóricas para além da conformação coercitiva, centralizadora, e de superação da dicotomia entre governantes e governados. $O$ oposto à Estadolatria é, portanto, o autogoverno, ou autogestão, em todos os sentidos da vida" (MORAES, 2018a, p. 38-39).

3 - Para estabelecer um paradigma político e filosófico anarquista, Wallace de Moraes procura consolidar uma discussão mostrando que a teoria libertária seria a única que busca romper tanto na teoria quanto na prática a dicotomia: governantes e governados. Nenhuma outra matriz teórica se propõe a romper com esse pressuposto.

4 - Revolução social iniciada no norte da Síria, na região de Rojava, nos escombros da guerra civil e da expulsão do Estado Islâmico, colocará esta ideia em movimento no seu sentido pleno, mas a sociedade curda vem construindo tais instituições como alternativa à repressão dos Estados-nação desde a década de 1990.

5 - Administração política não-estatal [...] flexível, multicultural, antimonopolista e orientado pelo consenso. A ecologia e o feminismo são pilares centrais (ÖCALAN, 2016, p. 27).

6 - Disponível em: http://www.educacao.sp.gov.br/reorganizacao. Acesso em: 17 maio 2018.

7 - "A governança jurídica é composta pelos seguintes atores: a) governantes jurídicos: Ministros do STF, dos tribunais superiores, magistrados em geral, Procuradoria Geral da República e membros do Ministério Público.

Essa governança é a responsável por aplicar e interpretar a lei. A artimanha da interpretação do Direito com criação de jurisprudências que devem ser obedecidas por todos, a justifica" (MORAES, 2018a, p. 68).

8 - Disponível em: http://www.seperj.org.br/admin/fotos/boletim/boletim778.pdf. Acesso em: 17 maio 2018.

9 - Disponível em: https://brasil.elpais.com/brasil/2015/12/18/politica/1450457576_034545.html. Acesso em: 18 maio 2018. 
10 - Disponível em: https://gauchazh.clicrbs.com.br/educacao-e-emprego/noticia/2016/05/o-quemove-as-ocupacoes-de-escolas-no-estado-5804779.html. Acesso em: 18 maio 2018.

11 - Disponível em: https://educacao.uol.com.br/noticias/2016/05/25/sem-acordo-estudantesdecidem-manter-ocupacao-de-54-escolas-no-ceara.html. Acesso em: 18 maio 2018.

12 - Disponível em: http://www.redebrasilatual.com.br/educacao/2016/05/mato-grosso-temprimeira-escola-ocupada-contra-parcerias-publico-privadas-8187.html. Acesso em: 18 maio 2018.

13 - Disponível em: http://www.diariodepernambuco.com.br/app/noticia/vidaurbana/2016/11/18/interna_vidaurbana,675702/audiencia-publica-debate-ocupacoes-estudantisnas-escolas-e-universid.shtml. Acesso em: 18 maio 2018.

14 - Disponível em: https://brasil.elpais.com/brasil/2016/10/13/politica/1476391382_358234.html. Acesso em: 18 maio 2018.

15 - Cabe dizer que os estudantes na maior parte das vezes nos materiais consultados não se intitularam anarquistas, libertários ou qualquer outra nomenclatura que remete a filosofia política que estamos tendo foco como problematização. As análises são feitas a partir das ações e dos contextos em geral.

16 - Empiricamente, a partir de relatos, citações, materiais audiovisuais, podemos perceber que, uma parte significativa das ocupações estudantis funcionaram por meio de autogestões em cada unidade educacional - por se tratar de um artigo e estudo preliminar, não poderemos aprofundar tanto nos detalhes. Essa autogestão das ocupações era realizada a partir da divisão de tarefas em comissões (segurança, comunicação, limpeza, organização, etc.). Vale salientar que os estudantes não reivindicavam o rótulo de anarquistas ou libertários, mas as práticas e organização política do espaço de resistência às políticas governamentais, que contrariavam os anseios da juventude de escolas públicas, eram de fato muito próximas ao pensamento e ações políticas da filosofia política libertária.

17 - Escolas Técnicas Estaduais que existem em São Paulo. Ver também em: https://educacao.uol.com.br/noticias/2016/05/04/entenda-o-que-esta-por-tras-das-ocupacoesdas-etecsem-sao-paulo.htm.

18 - Disponível em: https://esquerdaonline.com.br/2017/09/16/buenos-aires-uma-nova-onda-deocupacao-de-escolas/.

19 - Um exemplo significativo dessa hegemonia foi o $50^{\circ}$ Congresso da UNE em 2007, que elegeu sua primeira presidenta da entidade, uma jovem filiada ao PC do B. O partido ocupa e controla o cargo mais importante da entidade estudantil desde 1981 (GOHN, 2019, p. 46).

20 - Disponível em: https://www.brasildefato.com.br/2016/05/05/estudantes-ocupam-escolas-noparaguai-para-reivindicar-melhorias-na-educacao/. 


\section{REFERÊNCIAS BIBLIOGRÁFICAS}

BOOKCHIN, Murray. Ecologia social e outros ensaios. Rio de Janeiro: Achiamé, 2010.

BRINGEL, Breno. O futuro anterior: continuidades e rupturas dos movimentos estudantis do Brasil. EccoS Revista Científica, São Paulo, v. 11, n. 1, p. 97-121, 2009. Disponível em: https://www.redalyc.org/pdf/715/71512097006.pdf. Acesso em: set. 2020.

CASTELLS, Manuel. Redes de indignação e esperança: movimentos sociais na era da internet. Rio de Janeiro: Zahar, 2017.

MORAES, Wallace de. Governados por quem? Diferentes plutocracias nas histórias políticas de Brasil e Venezuela. Curitiba: Editora Prismas, 2018a.

MORAES, Wallace de. 2013 - Revolta dos Governados: ou, para quem esteve presente, revolta do vinagre. Rio de Janeiro: WSM Edições, 2018b.

DUPUIS-DÉRI, Francis. Quem tem medo do povo? Ágorafobia Política e Ágorafilia Política. Revista Estudos Libertários, Rio de janeirocidade, v. 1., n. 1, p. 9-35, 2019. Disponível em: https://revistas.ufrj.br/index.php/estudoslibertarios/article/view/24084/13884. pp. 9-35. Acesso em: set. 2020.

FINLEY, Moses I. Democracia antiga e moderna. Rio de Janeiro: Graal, 1988.

GOHN, Maria da Glória. Novas teorias dos movimentos sociais. São Paulo: Edições Loyola, 2014.

GOHN, Maria da Glória. Movimentos sociais e educação no Brasil. In: MEDEIROS, Jonas; JANUÁRIO, Adriano; MELO, Rúrion (orgs.). Ocupar e resistir: Movimentos de ocupação de escolas pelo Brasil (2015-2016). São Paulo: Editora 34, 2019, p. 37-52.

GRAEBER, David. Um projeto de democracia. São Paulo: Paz e Terra, 2015.

KROPOTKIN, Piotr. Palavras de um Revoltado. São Paulo: Editora Imaginário, 2005.

LAZARO, Helen. Um breve olhar sobre o pensamento educacional proudhoniano. In: PROUDHON, Pierre-Joseph; LAZARO, Helen; PASCHOETO, Luiza (orgs.). O pensamento de Proudhon em educação. São Paulo: Intermezzo Editorial, 2018, p. 9-26.

MALATESTA, Errico. Anarquismo e Anarquia. Faísca Publicações Libertárias, 2009. 
MIGUEL, Luis Felipe. "A democracia domesticada: bases antidemocráticas do pensamento democrático contemporâneo". Dados - Revista de Ciências Sociais, Rio de Janeiro, v. 45, n. 3, p. 483-511, 2002.

ÖCALAN, Abdullah. Confederalismo Democrático. Rio de Janeiro: Rizoma, 2016.

RODRIGUES, Glauco Bruce (2004). Territórios libertários: a experiência anarquista de autogestão na cidade de Barcelona durante a guerra civil espanhola (1936 - 1939). In: CIDADES, Revista Científica/Grupo de Estudos Urbanos - vol. 1, n. 1. Presidente Prudente: Grupo de Estudos Urbanos - v. 9, n. 15, p. 259-295.

SANTOS, Boaventura de Sousa. Os Novos Movimentos Sociais. In: LEHER, Roberto; SETÚBAL, Mariana (orgs.) Pensamento crítico e Movimentos Sociais: diálogo para uma nova práxis. São Paulo: Cortez Editora, 2005, p. 174-189.

SILVA, Peterson Roberto da. O Anarquismo e a Legitimidade: tensões pós-modernas. 2018. Dissertação (Mestrado em Sociologia Política) - Centro de Filosofia e Ciências Humanas (CFH), Universidade Federal de Santa Catarina (UFSC), Santa Catarina, 2018.

ZIBAS, Dagmar M. L.. "A Revolta dos Pinguins" e o novo pacto educacional chileno. Revista Brasileira de Educação, São Paulo, v. 13, n. 38, p. 199-220, 2008.

\footnotetext{
Gullherme Xavier de Santana: Doutorando em História Comparada no Programa de Pós-Graduação em História Comparada do Instituto de História da Universidade Federal do Rio de Janeiro (PPGHC-IH-UFRJ); bolsista da CAPES; membro-pesquisador do Observatório do Trabalho na América Latina da UFRJ (OTAL-UFRJ) e do Coletivo de Pesquisas Decoloniais e Libertárias da UFRJ (CPDEL-UFRJ); Mestre em Educação no Programa de Pós-Graduação em Educação da Universidade Federal do Rio de Janeiro (PPGE-UFRJ) na linha de Políticas e Instituições Educacionais; Possui graduação em Ciências Sociais pela Universidade Federal do Rio de Janeiro (2009). Atualmente é professor do Governo do Estado do Rio de Janeiro. Tem experiência na área de Sociologia, com ênfase em Sociologia.

Orcid: https://orcid.org/0000-0001-5497-2399

E-mail: suidesantana@gmail.com
}

Este periódico utiliza a licença Creative Commons Attribution 3.0, para periódicos de acesso aberto (Open Archives Iniciative - OAI). 